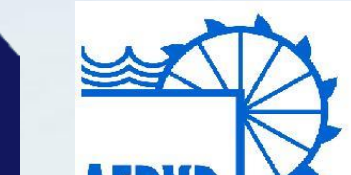 ARro
}

XXXIV Congreso Nacional de Riegos Sevilla 2016
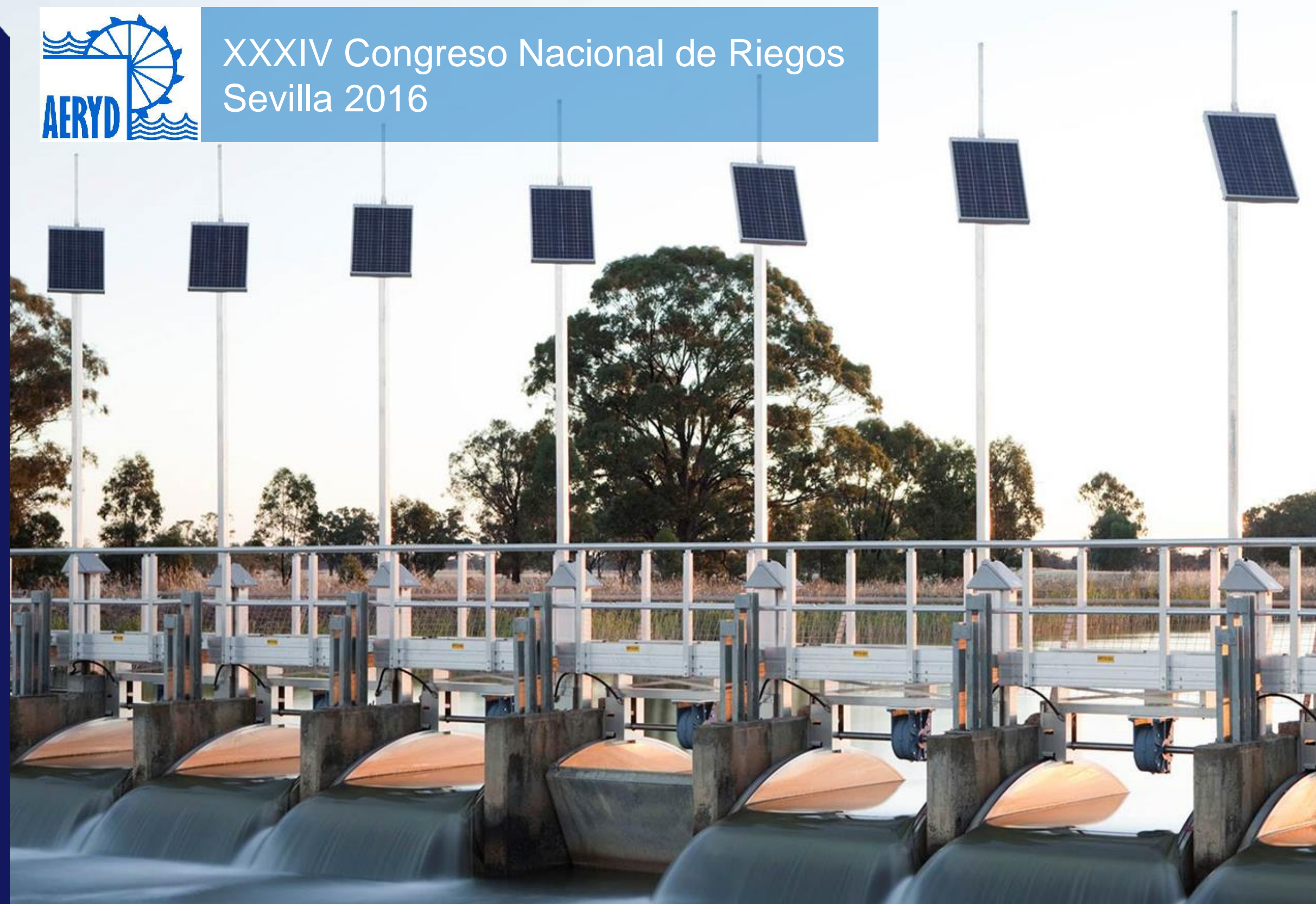

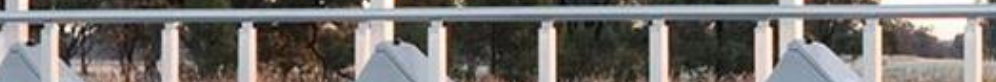

西

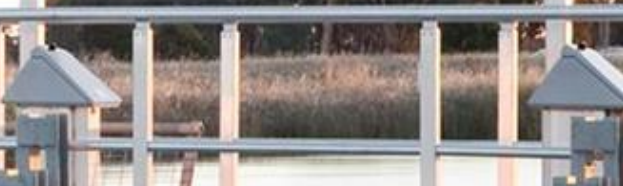

\section{La Gestión De Las Redes de Riego}




\section{Método tradicional del Riego por Gravedad}

Cuando hay recursos de agua en abundancia, se puede entregar caudales mayores que los pedidos, asegurando agua a todos los usuarios a lo largo del sistema.

- Grandes pérdidas por derrames

- Baja eficiencia

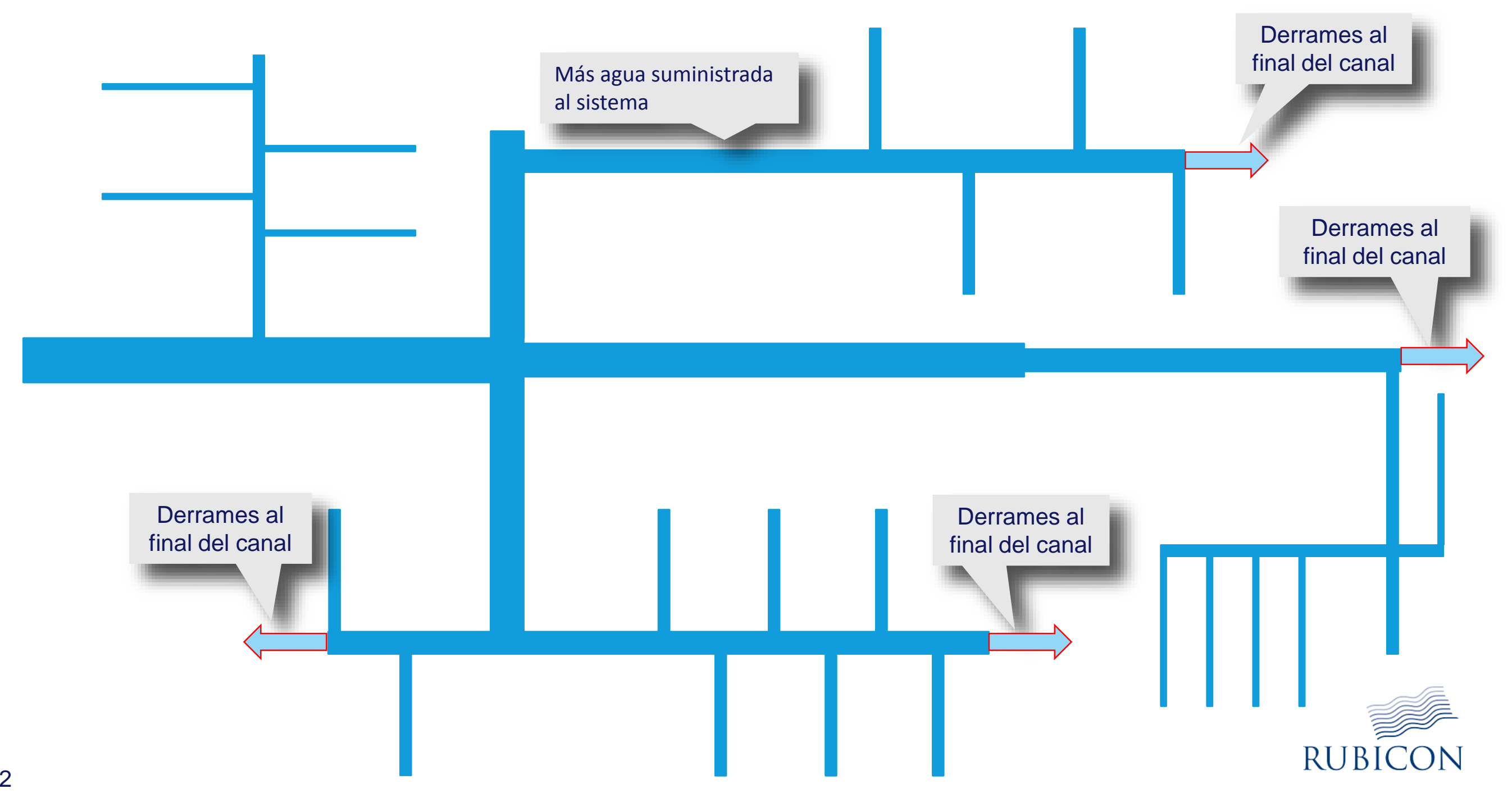




\section{Los turnos de riego son inflexibles y causan un uso excesivo del agua}

Los usuarios se ven forzados a utilizar toda el agua disponible, ya que sino hay que esperar al próximo turno.

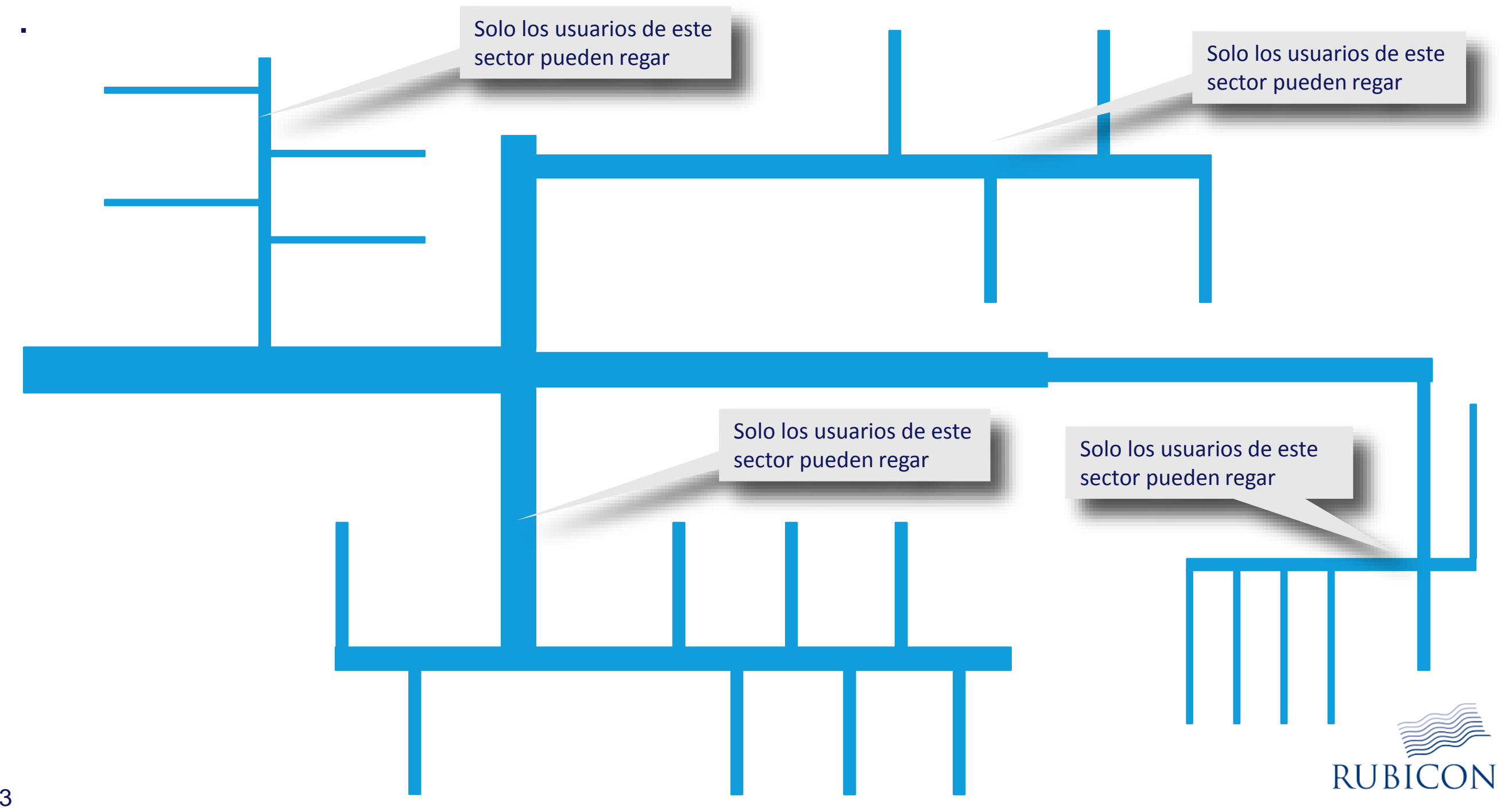




\section{Mejor Servicio $=$ Sistemas Presurizados}

Dado que los Sistemas de gravedad gestionados manualmente no proveen un servicio adecuado, la única respuesta es cambiar gravedad por presurización

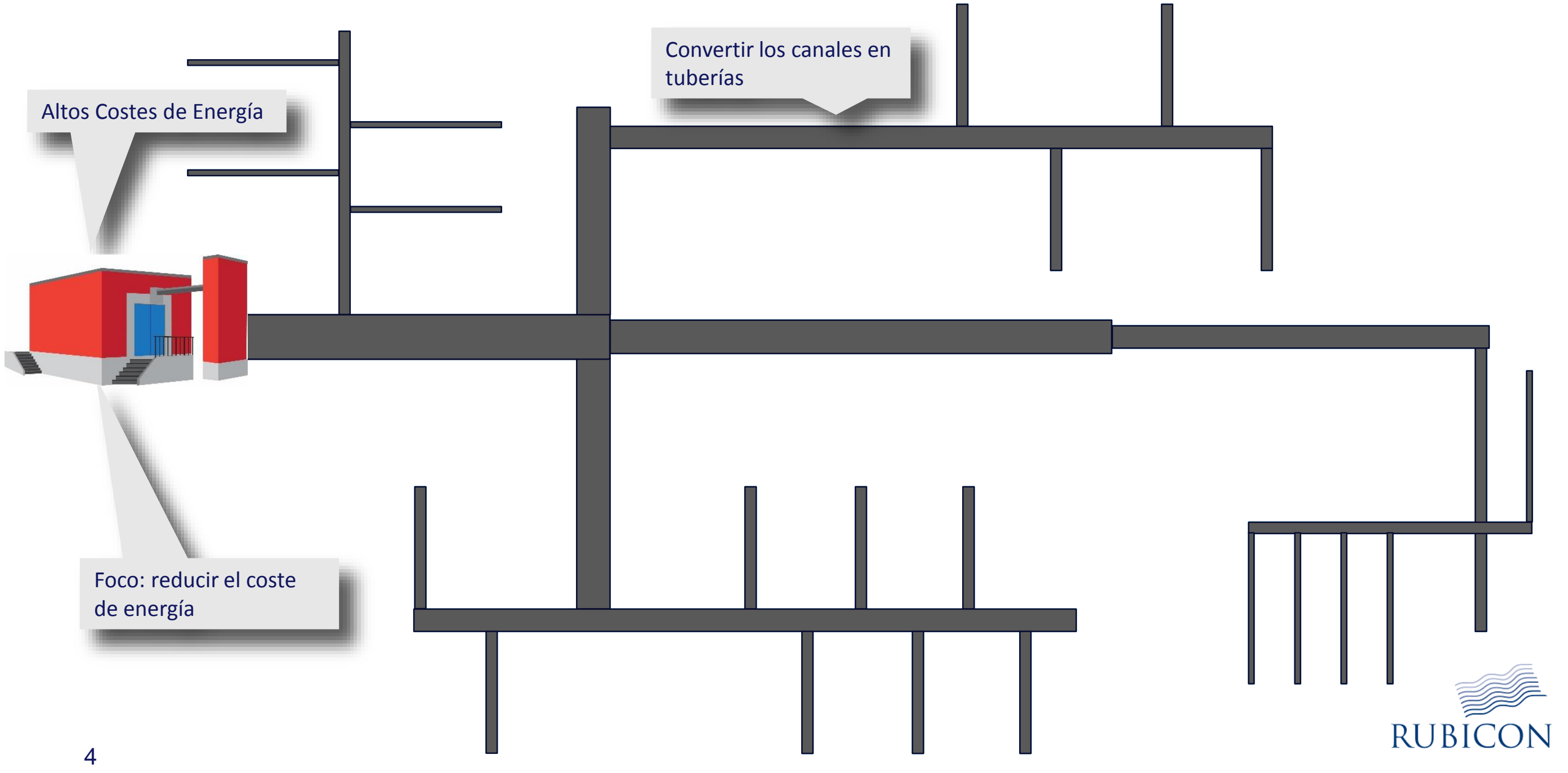




\section{La Solución de Rubicon}

Rubicon ha desarrollado tecnología y software para aumentar la eficacia de los sistemas de gravedad
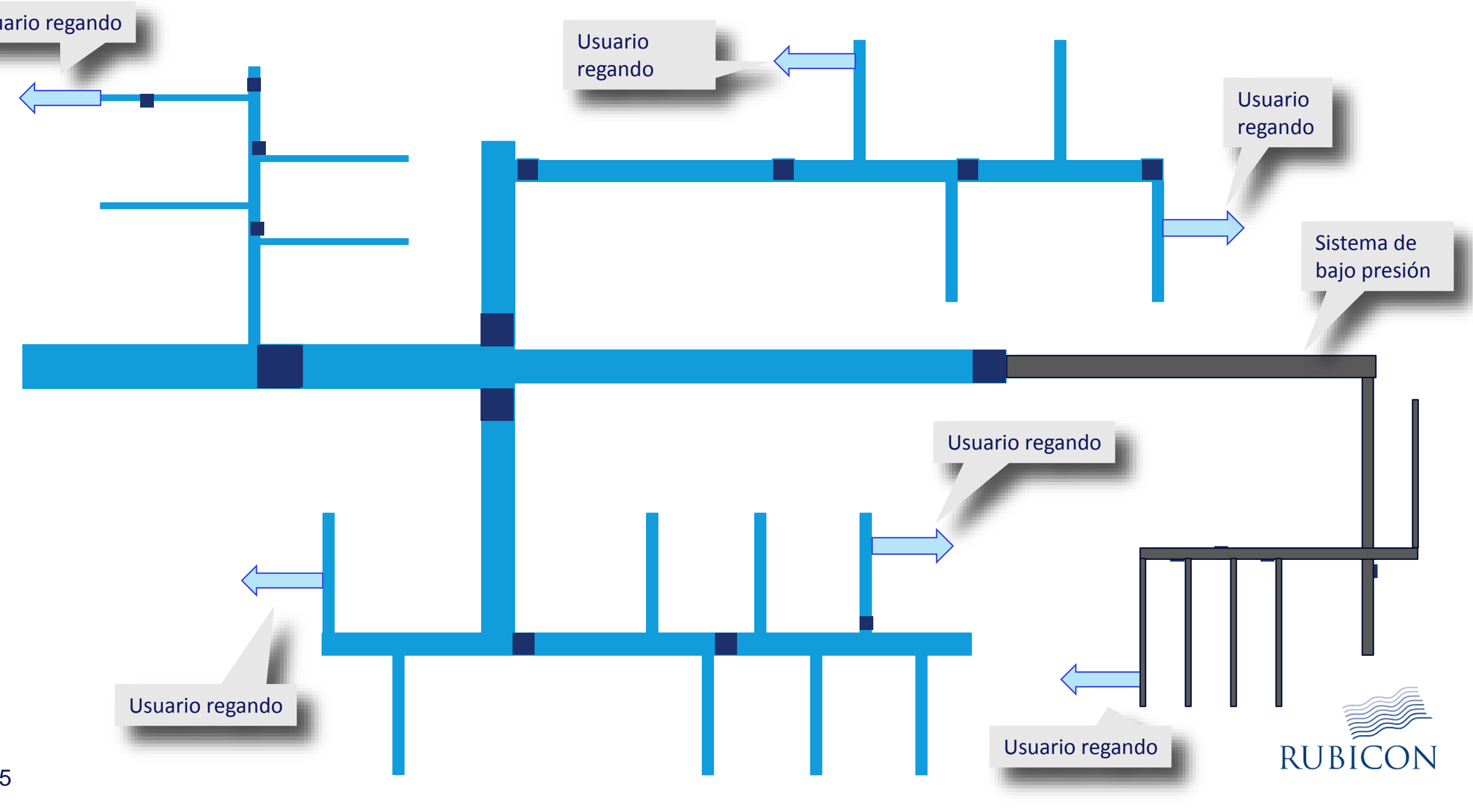


\section{El Mensaje Clave}

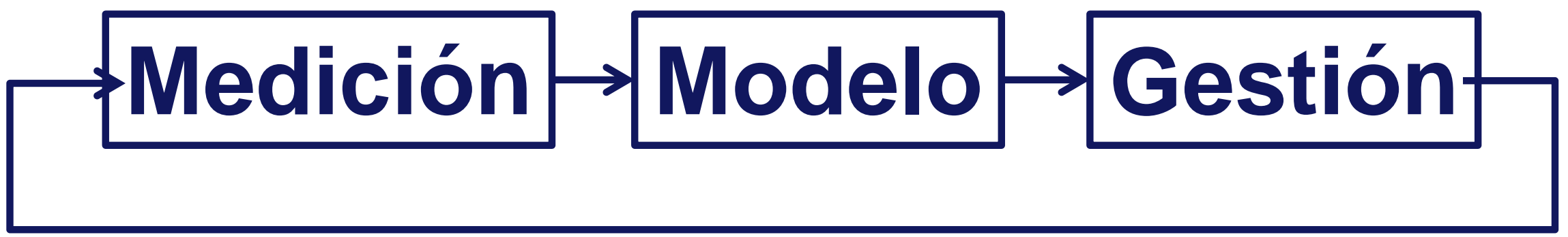

Ingeniería de sistemas para la gestión del canal

-Utilizar toda la capacidad física del sistema de canal abierto

$\checkmark$ Aumentar la productividad del agua o el ahorro de agua

Proporcionar la rendición de cuentas del agua

Eliminar el riesgo de la agricultura de riego

Ahorre energía (menos / no bombeo)

Habilitar un mercado del agua (marco de política)

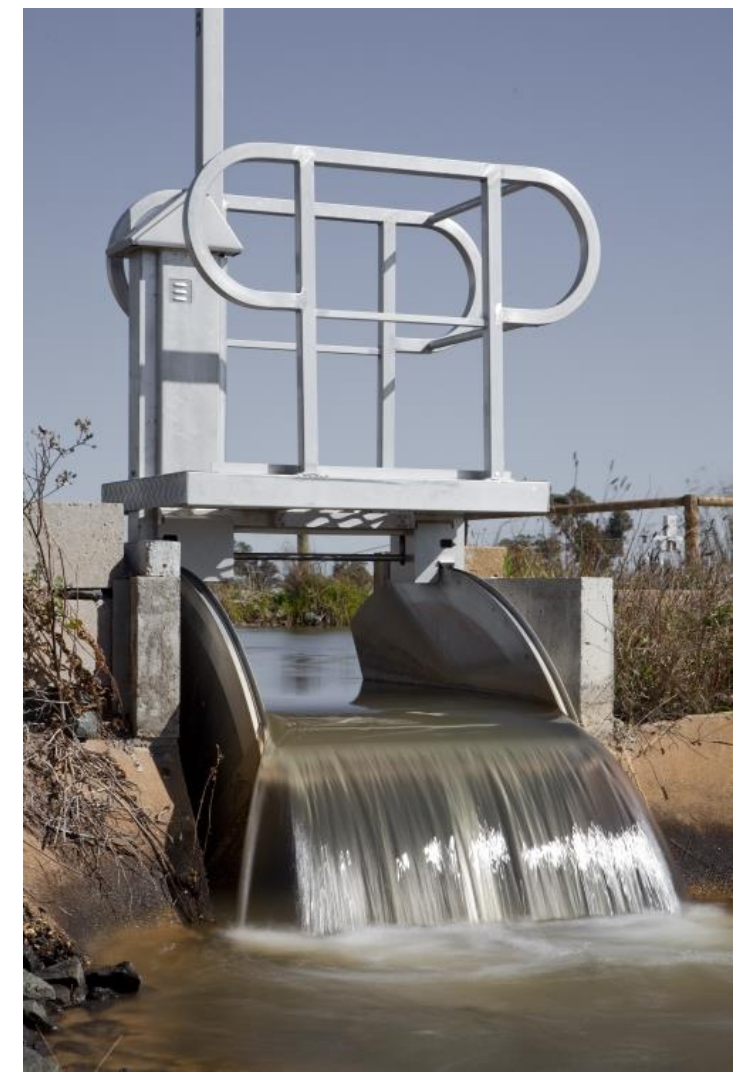




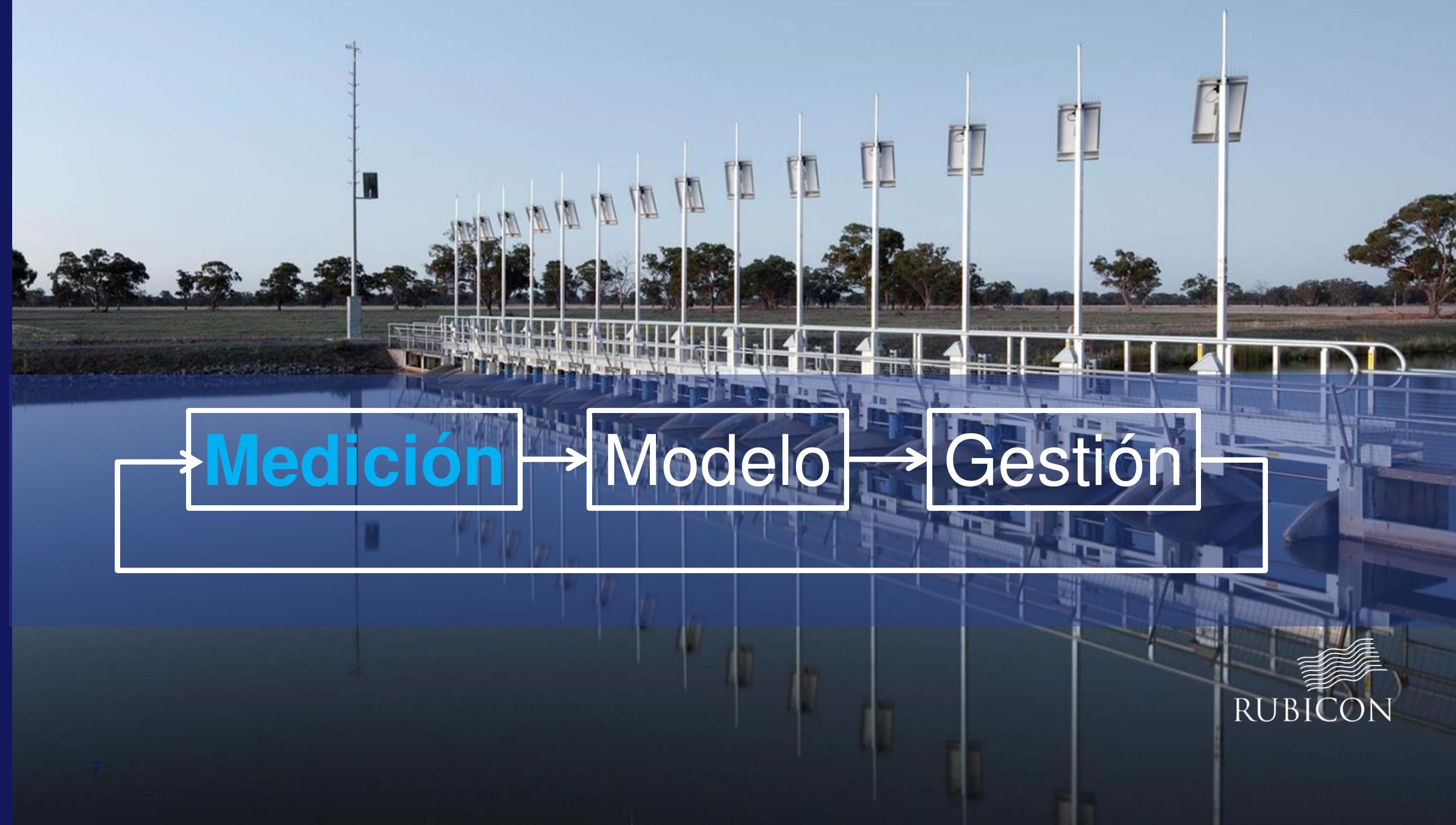




\section{Dispositivos innovadores}

\section{FlumeGate $^{\mathrm{TM}}$}

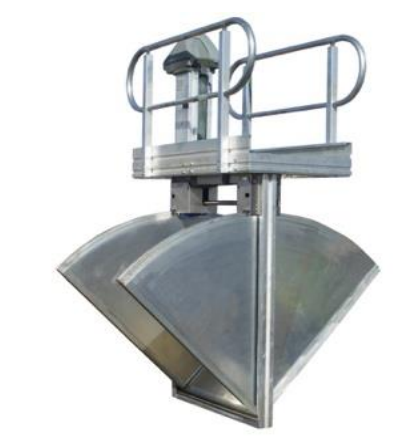

Medidor y control de caudal
SlipMeter $^{\mathrm{TM}}$

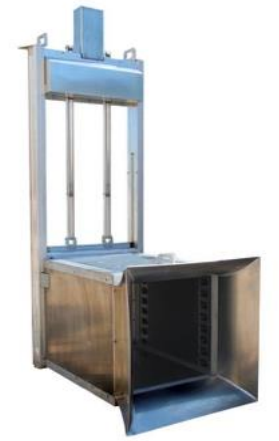

Medidor y control de caudal

FlumeMeter $^{\mathrm{TM}}$

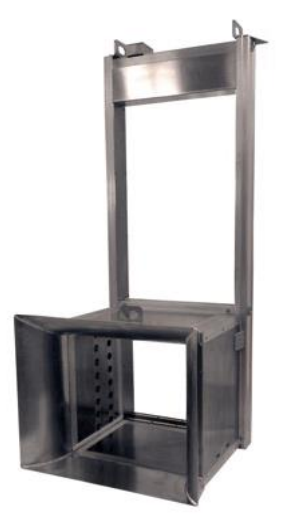

Medidor
BladeMeter $^{\mathrm{TM}}$

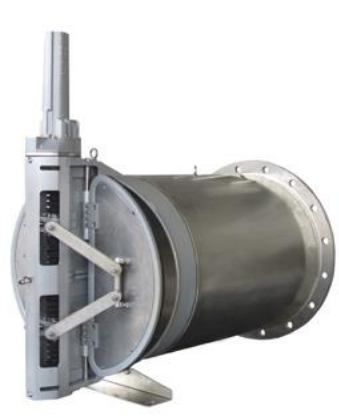

Medidor y control de caudal

Sonaray ${ }^{\circledR}$ Pipe Meter

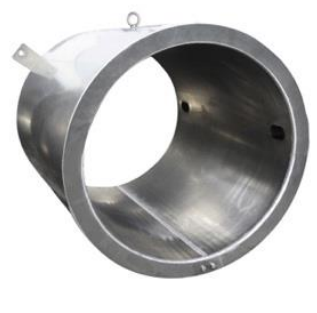

Medidor 


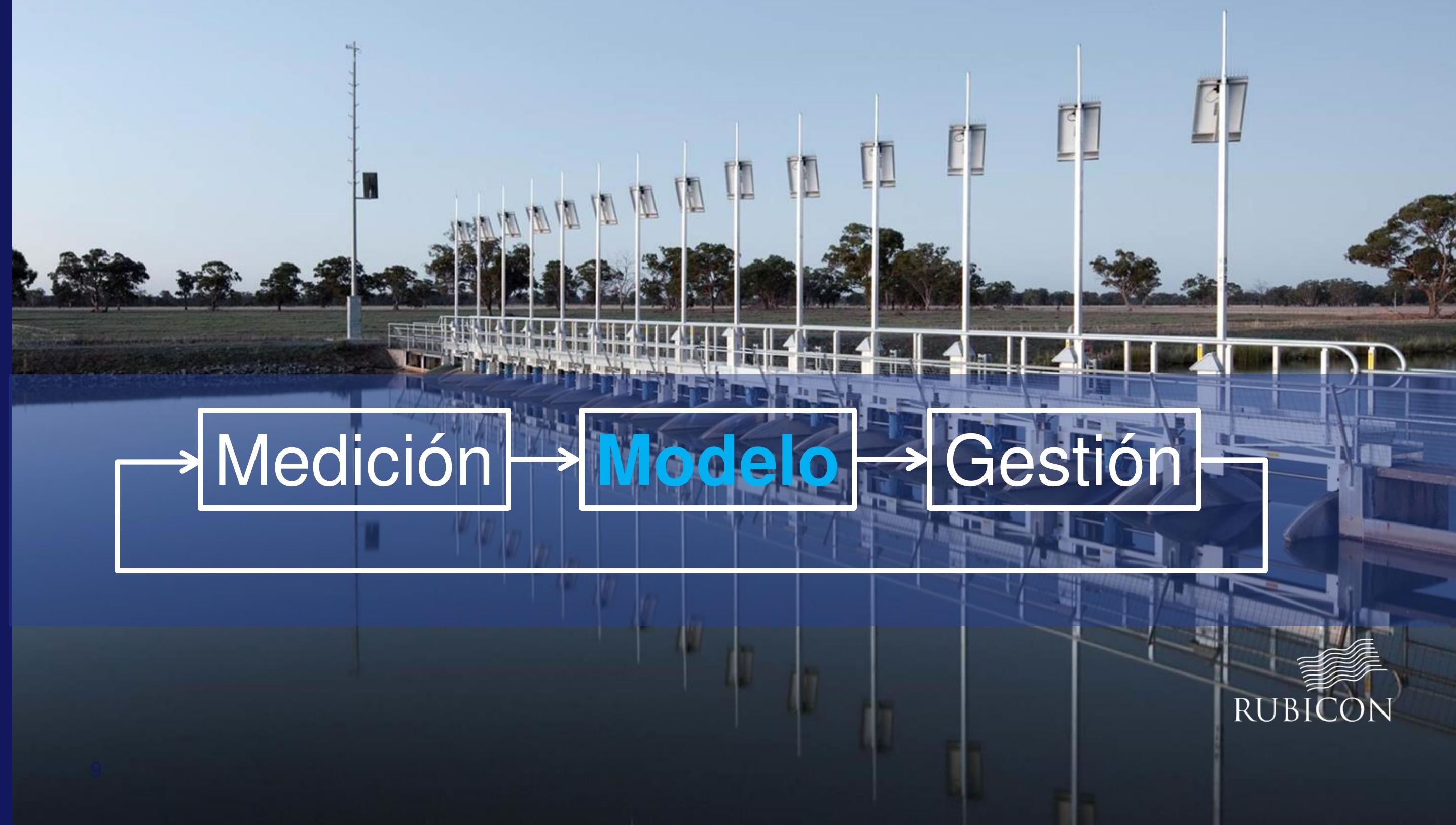




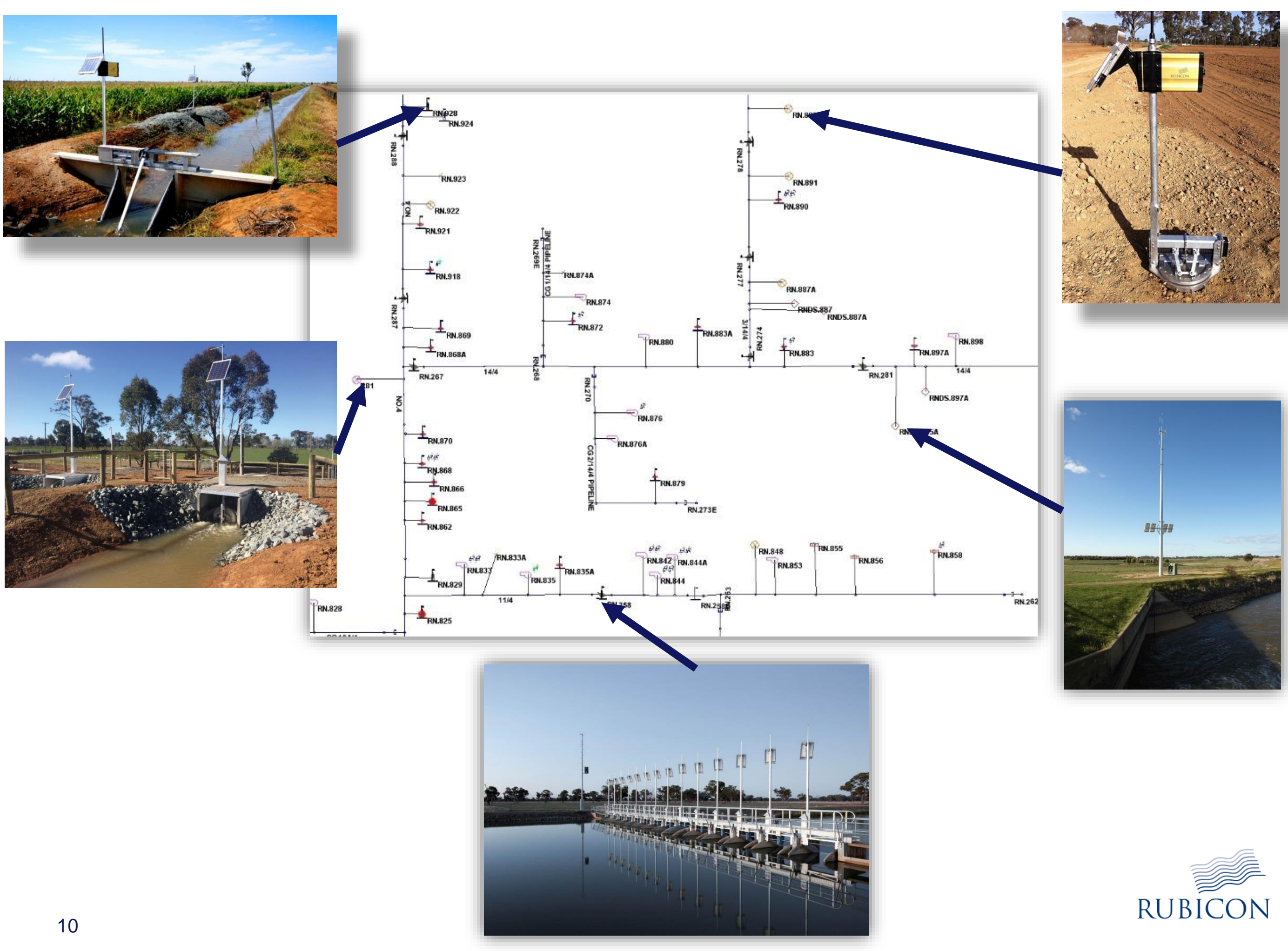



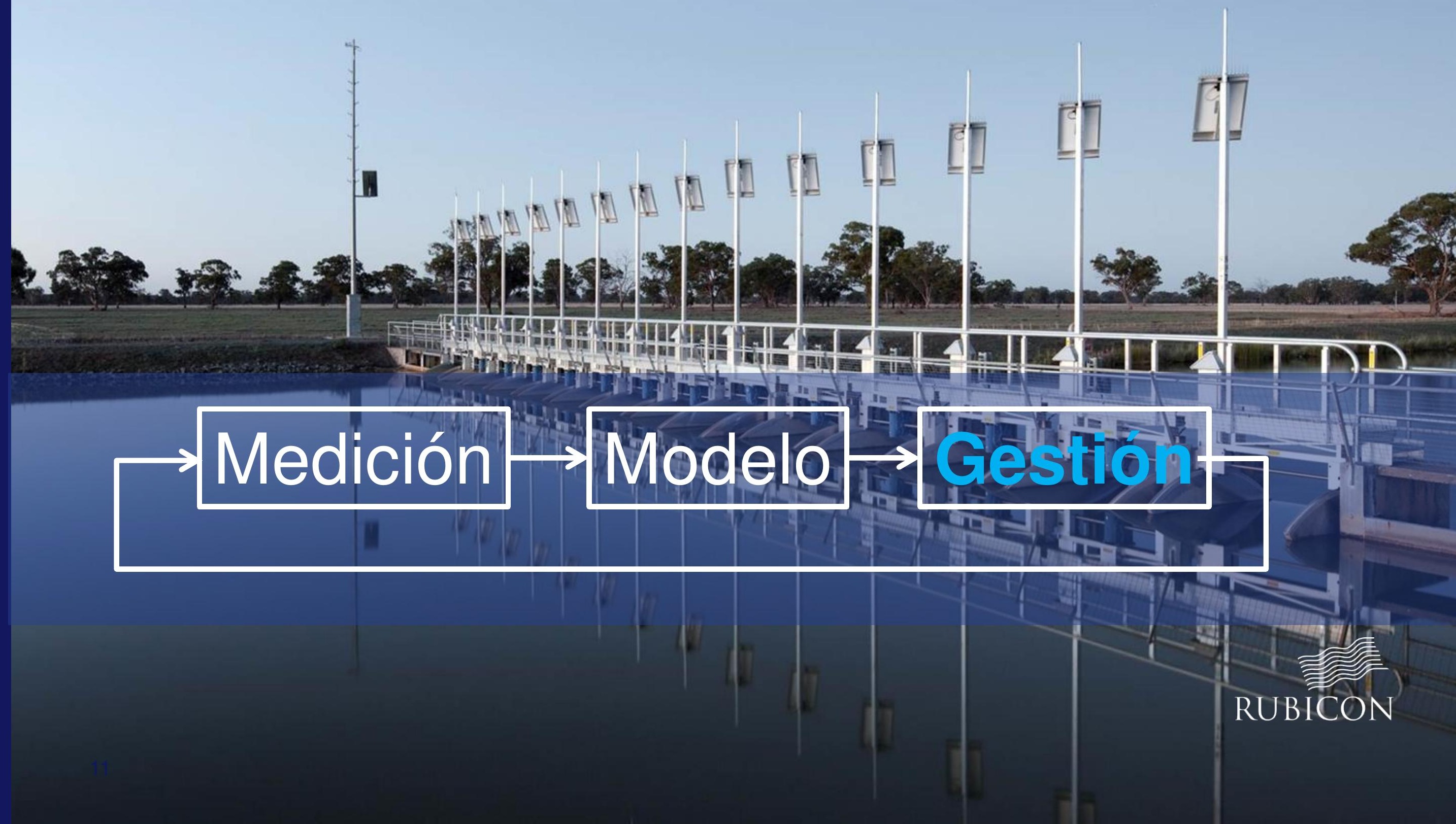


\section{La tecnología Total Channel Control (TCC)}

- Una idea de la complejidad del sistema

- GMW 6.000 kilómetros

- 15k Sitios agrícolas

- 20k sitios con medición del caudal

- 6k Restricciones de nivel de agua

- 20k estados modelo

- 300k estados de control

- 400k variables para definir el sistema

- 2,5 M seguido de variables;

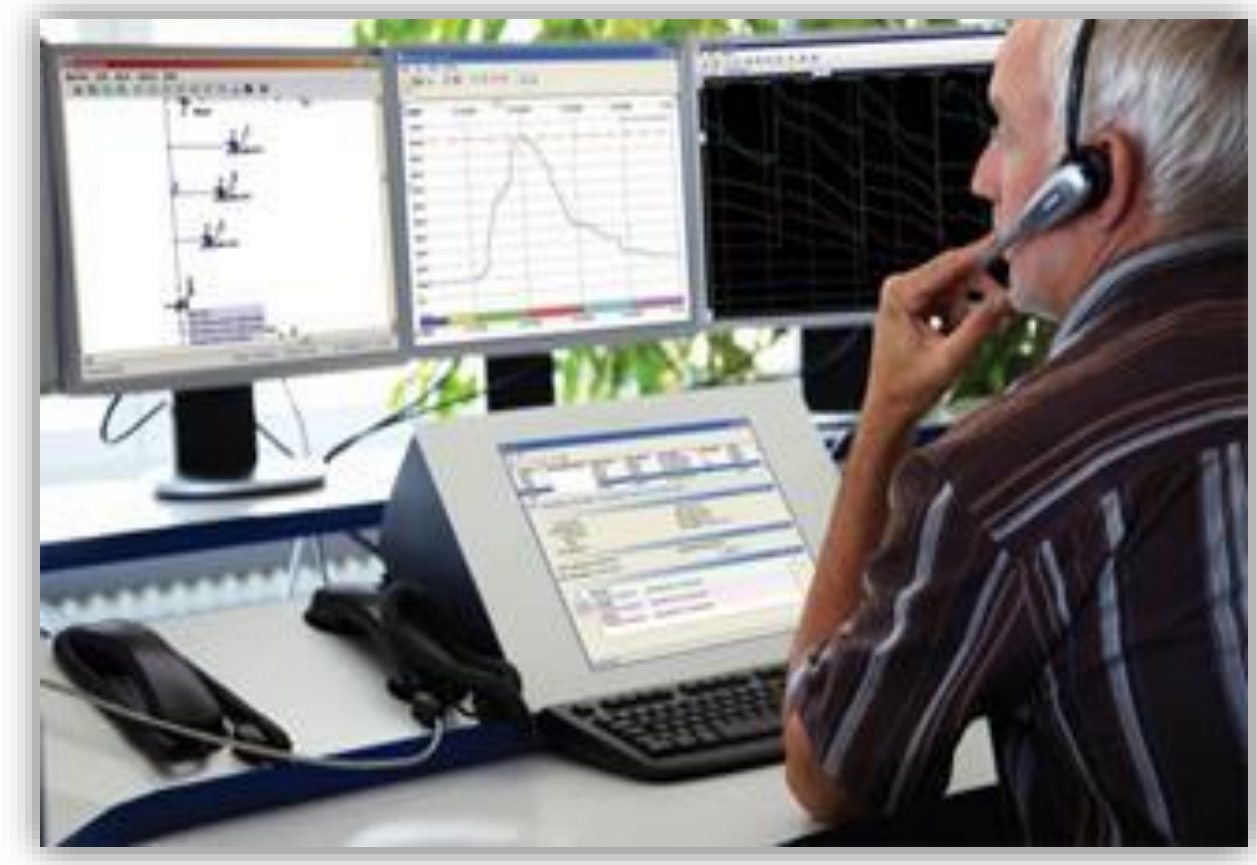

- 8 mensajes (basado en eventos) / por hora / por sitio? (700M mensajes durante una campaña, $\approx 200 \mathrm{~Gb}$ )

- Potencial del software $\approx 50 \%$ complejidad de SAP $\approx 100$ veces de Windows 


\section{G-MW's Modernised Irrigation Delivery System}

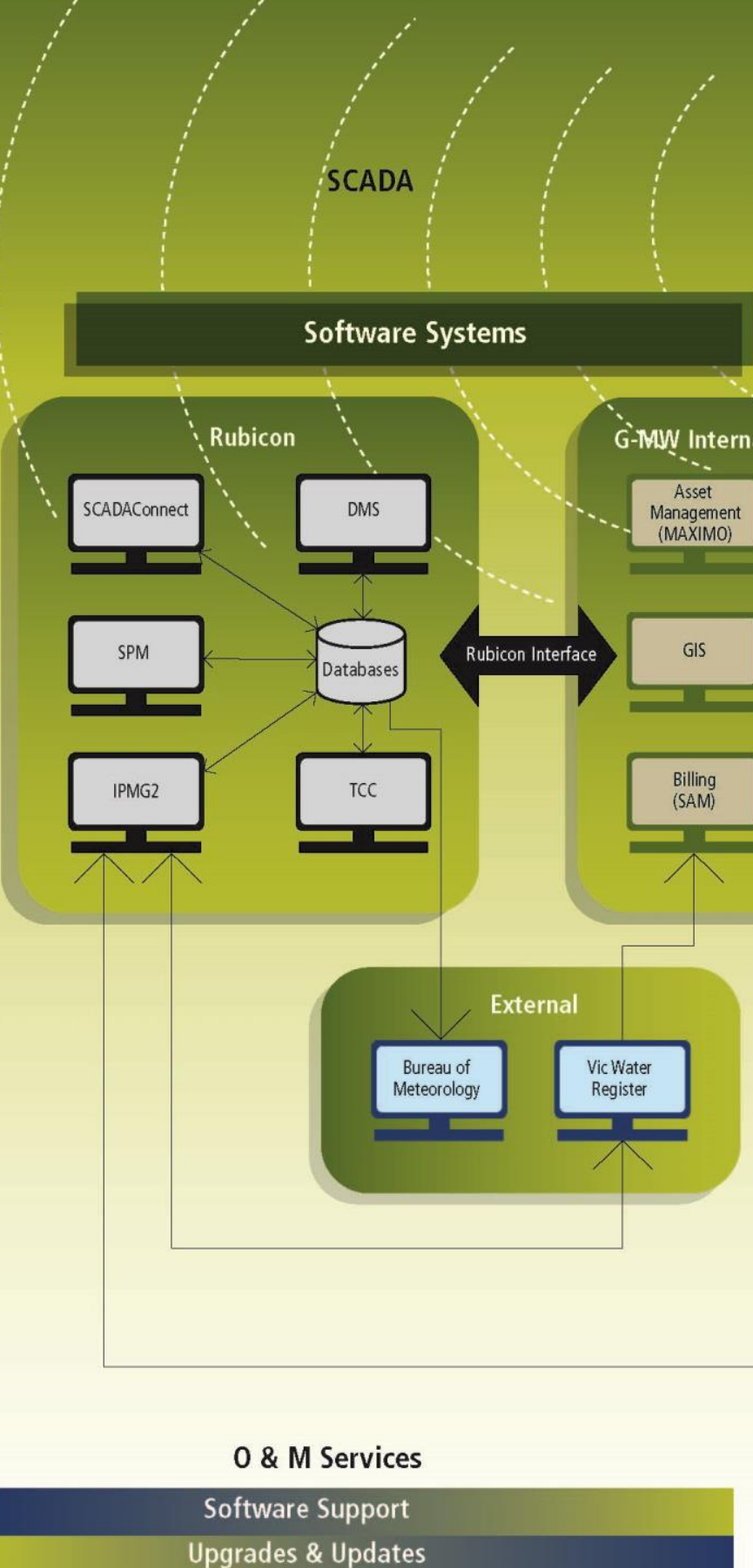

One of the world's largest SCADA systems 10,000 sites

1.2 million tags

500 million time series data points

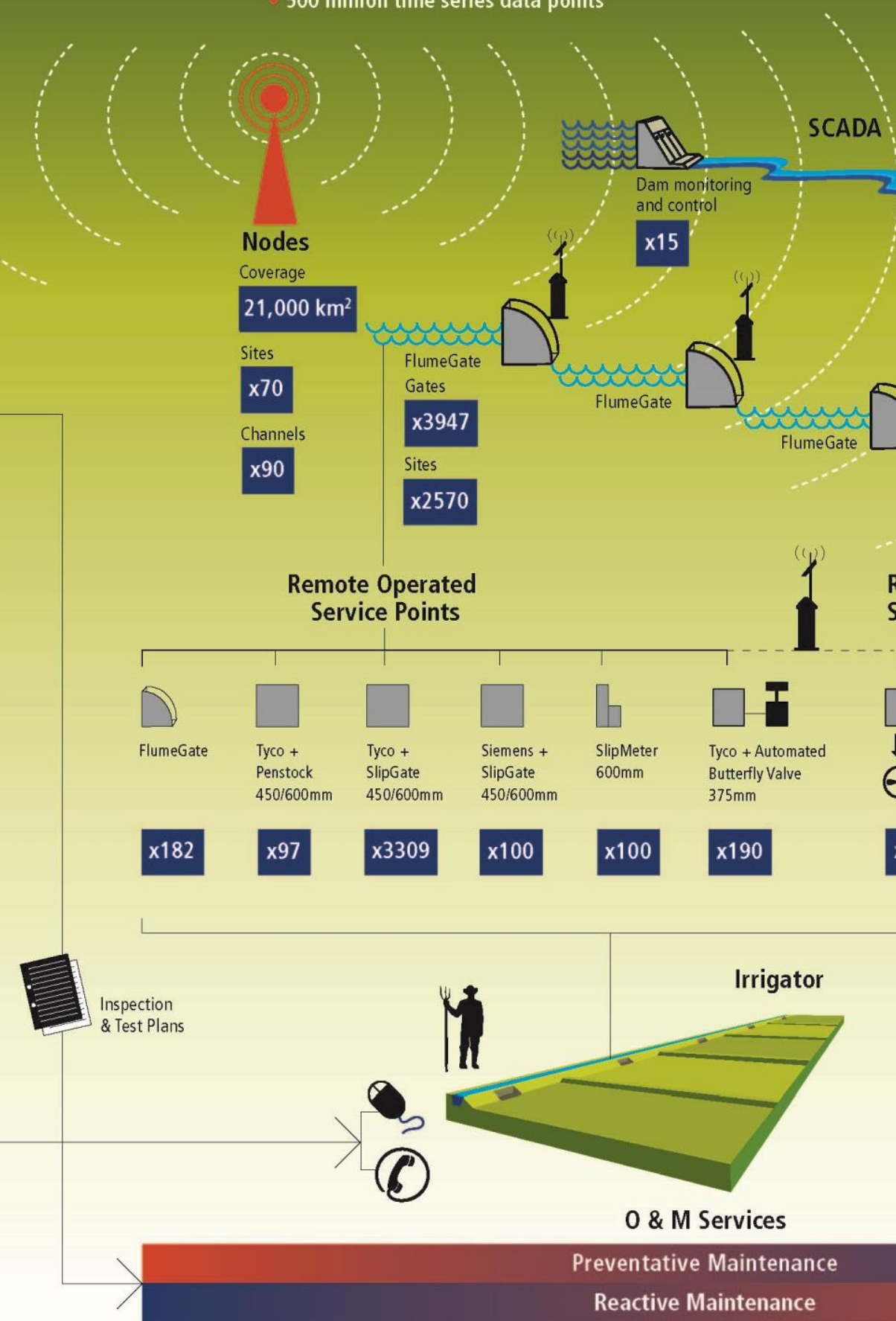




\section{KPMG - Software Size \& Complexity Report}

\subsection{INDUSTRY BENCHMARKS}

Estimated Size of Select Applications

\begin{tabular}{|l|l|}
\hline Application & Function Points \\
\hline US Air Traffic Control & 306,324 \\
\hline SAP & 296,764 \\
\hline Microsoft XP Operating System & 126,788 \\
\hline NSA Code Decryption & 35,897 \\
\hline FBI Fingerprint Analysis & 25,075 \\
\hline Nuclear Reactor Controls & 19,084 \\
\hline NASA Hubble Controls & 21,632 \\
\hline LINUX Operating System & 17,672 \\
\hline Oil Refinery Process Control & 17,203 \\
\hline ITT Systems 12 telecom & 17,002 \\
\hline Google Search Engine & 16,895 \\
\hline Patriot Missile Controls & 15,392 \\
\hline
\end{tabular}

Source: "Applied Software Measurement" Caper Jones, 2008
September 2011

\section{Rubicon TCC Solution 70,000 Function Points}

Industry standard approach considered

- Executable lines of code

- Programming languages

- System complexity

Industry benchmarks are approximately

- $\$ 20 \mathrm{M}$ for 10,000 Function Points

- $\$ 240 \mathrm{M}$ for 100,000 Function Points

- Relationship not linear

Does not include value of IP \& Patents

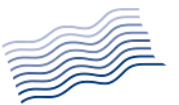

RUBICON 


\section{La piedra angular de la solución de control de red de canales de Rubicon}

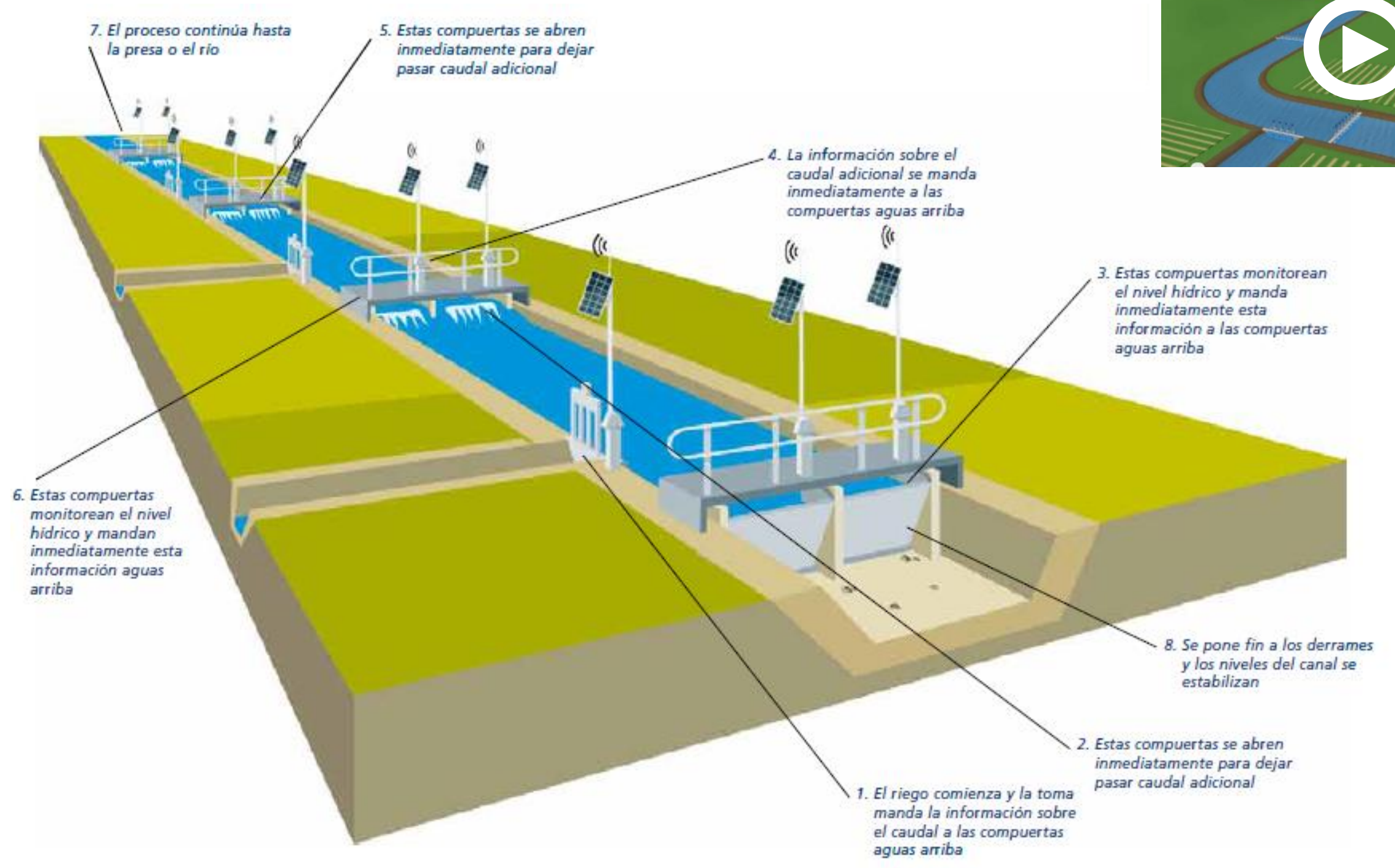




\section{Confluent: el software para la gestión integral}

Un base de datos que representa toda la información de una cuenca incluyendo los canales, las CR, los regantes, las parcelas, los cultivos, las peticiones, las dotaciones el uso de agua y varios módulos para procesar la información.

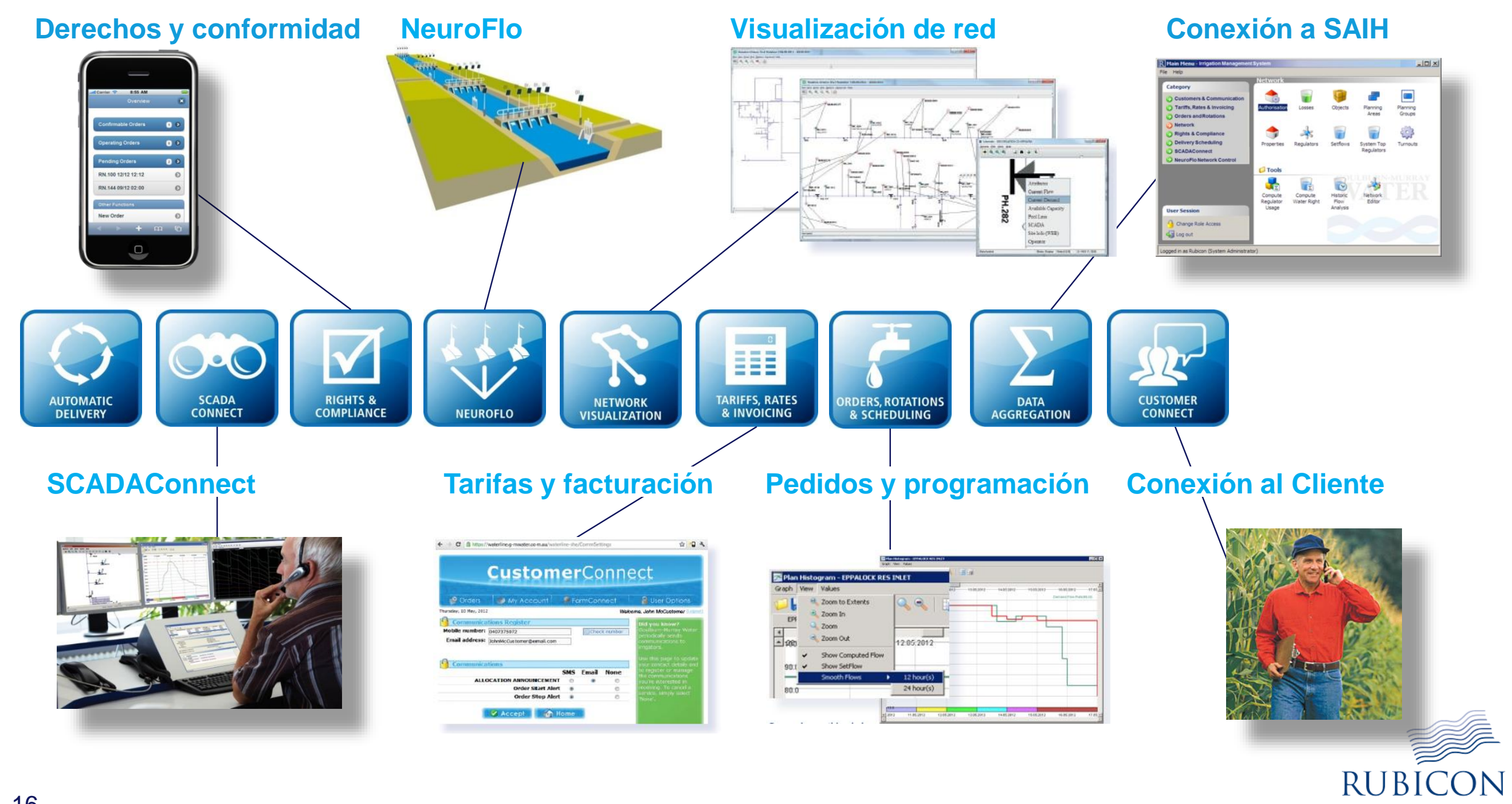




\section{Confluent gestiona la demanda sin exceder las limitaciones de los canales}

Se puede recibir peticiones en tiempo real y programarlas automáticamente para suministrar el agua a la demanda

Confluent

$\checkmark$ colecta peticiones vía telefónica, vía sistema de reconocimiento de voz o a través del internet;

programa las peticiones basadas en modelos hidráulicos de cada tramo

$\checkmark$ asegura que no se den desbordamientos

$\checkmark$ permite que el regante tenga flexibilidad y por ello utilice menos agua y produzca más

$\checkmark$ evita el coste de la construcción de balsas de regulación

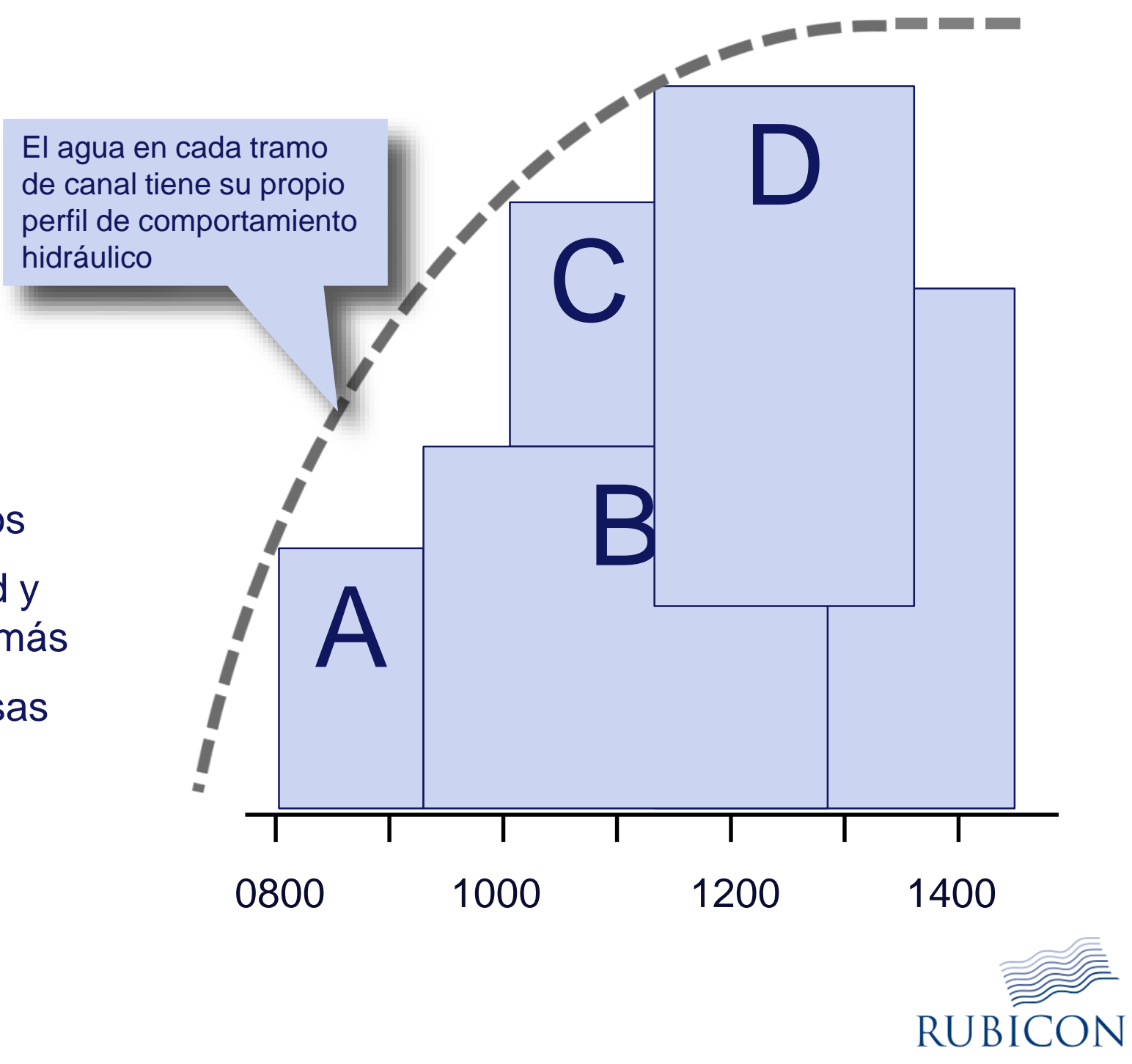




\section{Opción híbrida: Gravedad / bomba}

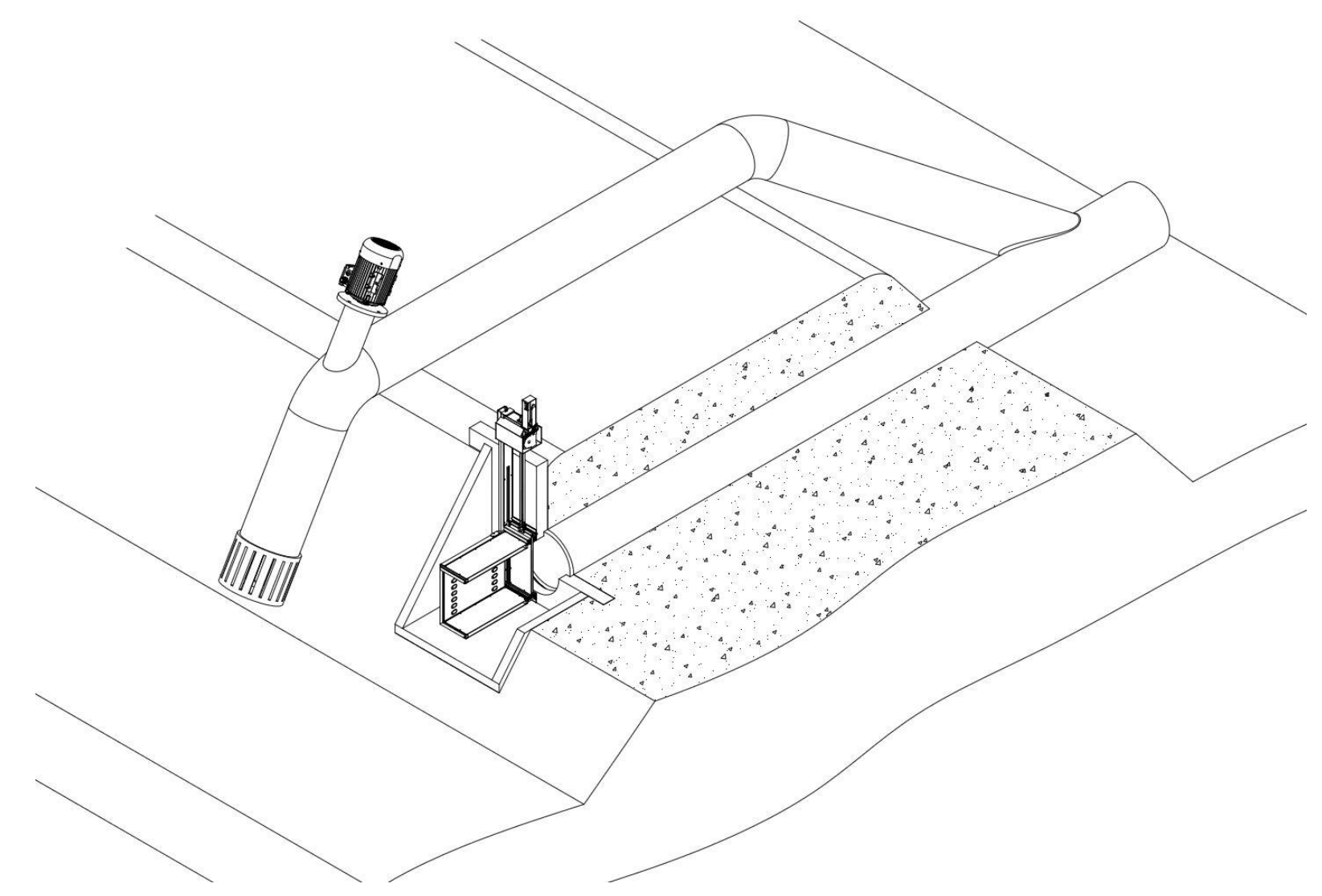

- Minimiza los costos de energía en comparación con la tubería a presión

$\checkmark$ Se puede establecer un régimen tarifario, donde los regantes pueden elegir la opción de bombeo en el pedido $\mathrm{Si}$ el caudal no disponible

$\checkmark$ La infraestructura de la bomba se puede añadir en cualquier etapa y a discreción los regantes 


\section{Opción híbrida: Gravedad / bomba}

La demanda supera la capacidad del sistema

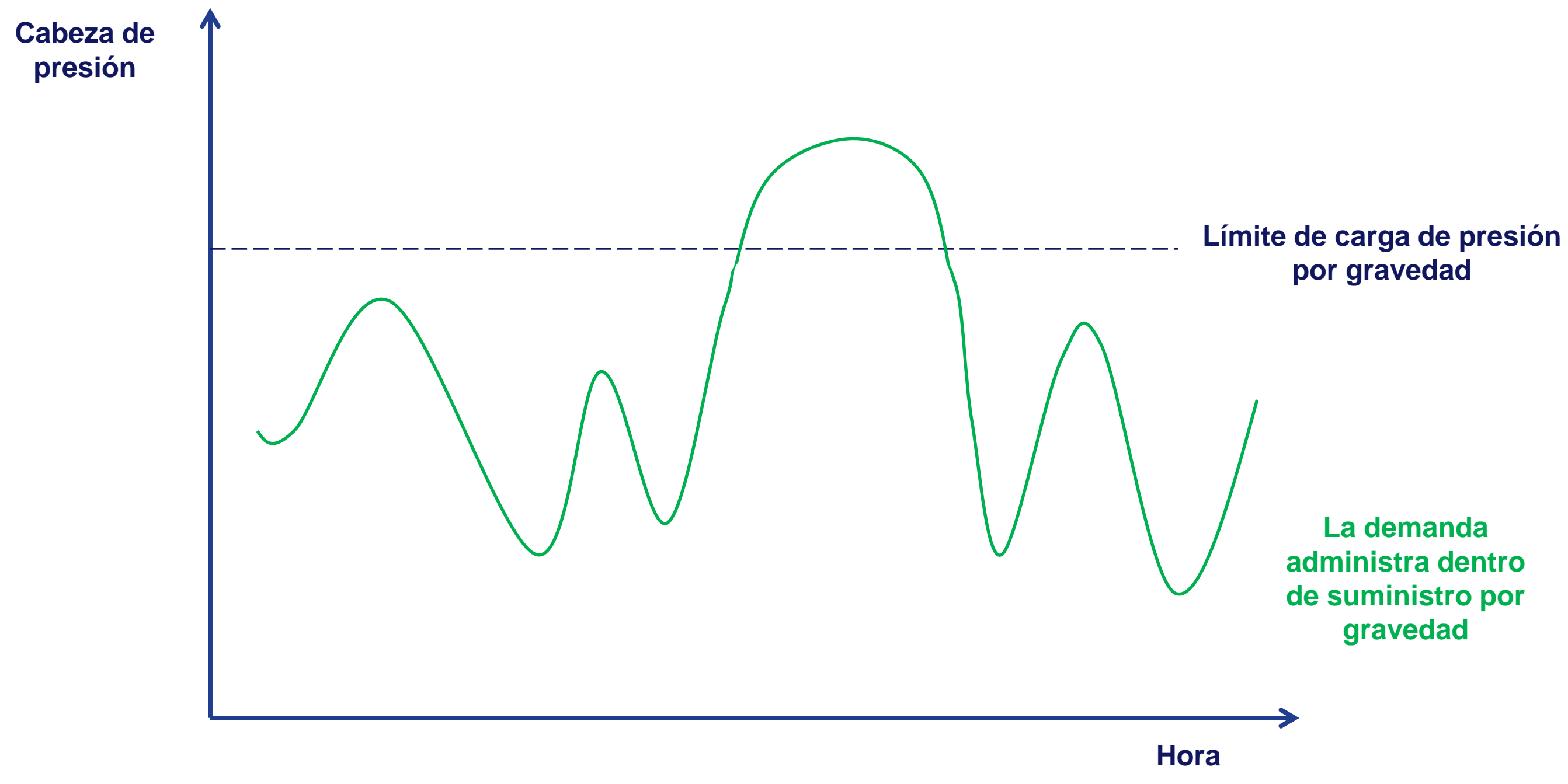




\section{Opción híbrida: Gravedad / bomba}

La demanda supera la capacidad del suministro por gravedad - reprogramar las solicitudes de entrega

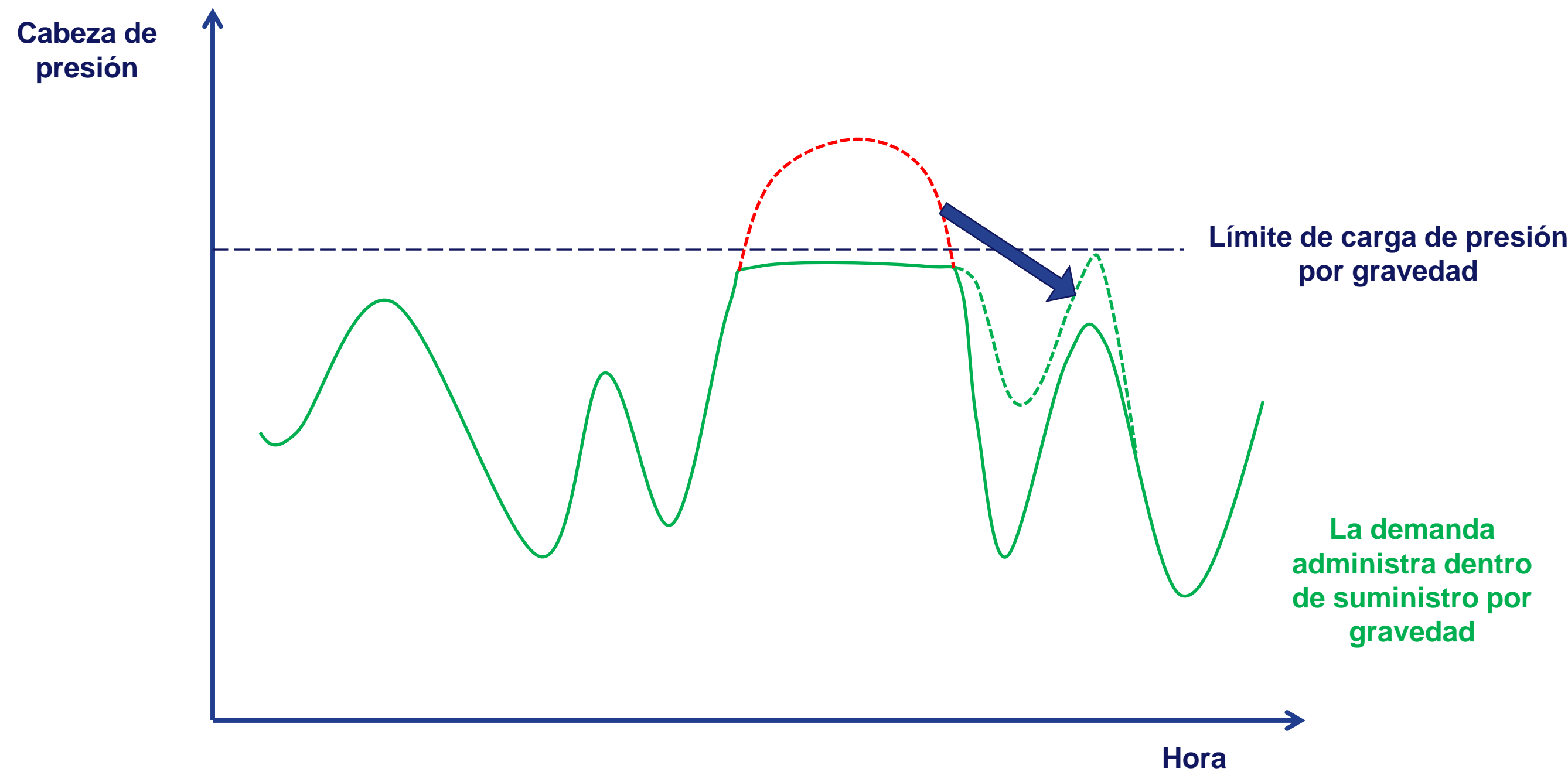




\section{Opción híbrida: Gravedad / bomba}

La demanda supera la capacidad del suministro por gravedad - bomba híbrida

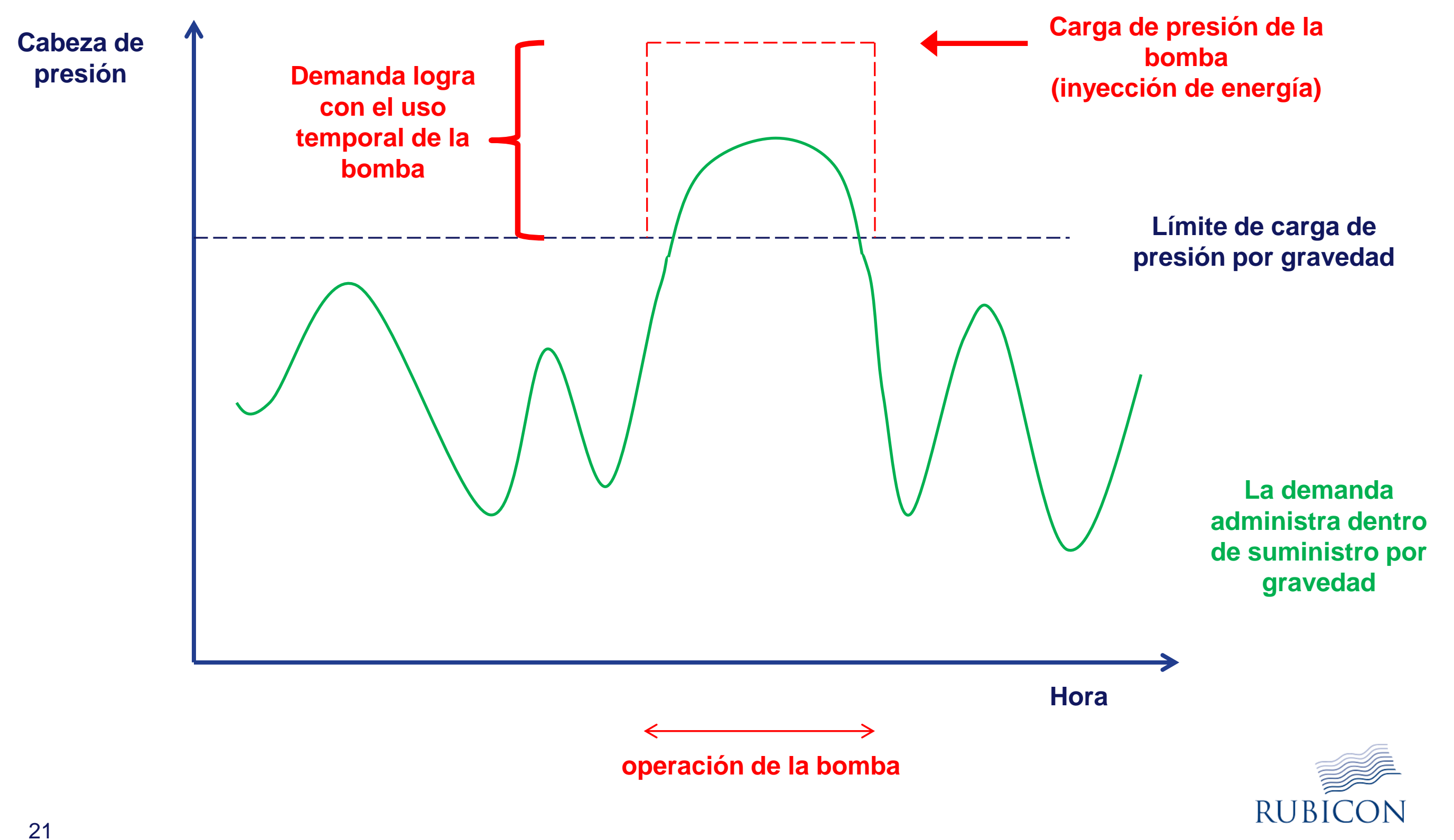




\section{Un caudal no fiable conlleva mayor consumo agua}

Si los niveles de los canales varían, los agricultores reciben de caudal inconsistente y de baja y así deben salir de su agua por más tiempo para cubrir sus tierras a menudo resulta en un exceso de infiltración
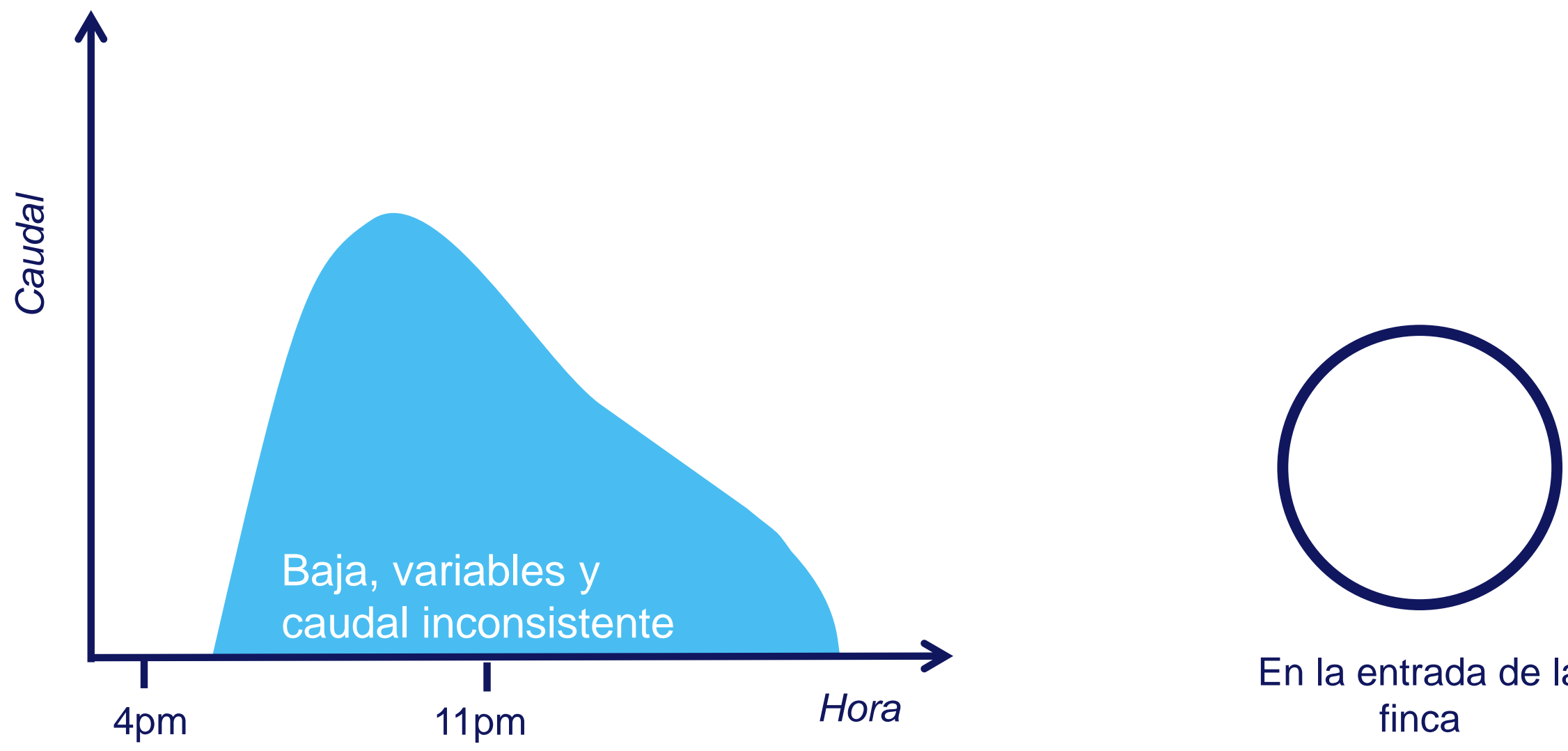

En la entrada de la finca 


\section{Caudal no fiable también se traduce en la baja productividad de los cultivos}

$\checkmark$ El agricultor debe regar en exceso para asegurar toda la cosecha se alcanza, a menudo también resulta en la escorrentía

$\checkmark$ El frente de la cosecha queda ahogado

$\checkmark$ Utilizando del agua en excesivos se resulta en la nitrificación del suelo (nutrientes NPK en solución y lixiviar de distancia) y salinización (eleva el nivel freático trayendo sales, que hace que la planta al estrés)

$\checkmark$ Cultivos estresados crecen menos y son más afectados por insectos y enfermedades......

Anegamiento y la infiltración

en la parte delantera

Nutrificación y / o salinización del suelo pueden resultar

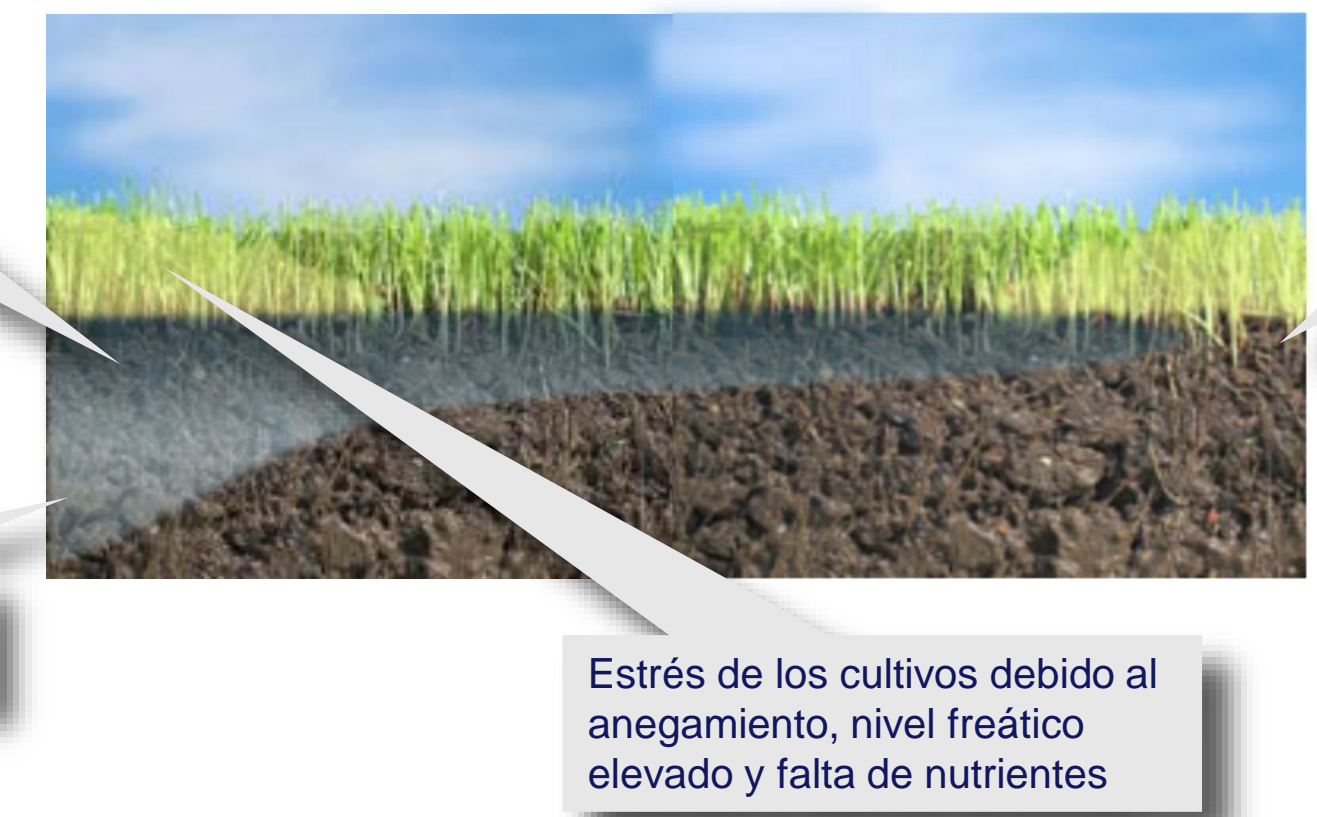

elevado y falta de nutrientes
La escorrentía (debido a la mala sincronización de corte) significa valioso fertilizante se elimina por lavado y puede contaminar los cursos de agua 


\section{El control de la red asegura un alto caudal y constante}

Menos agua se utiliza y la productividad de los cultivos mejora porque los niveles de los canales se mantienen altos y estables para suministrar exactamente el agua que necesita el agricultor cuando necesitaban a caudal elevado y constante
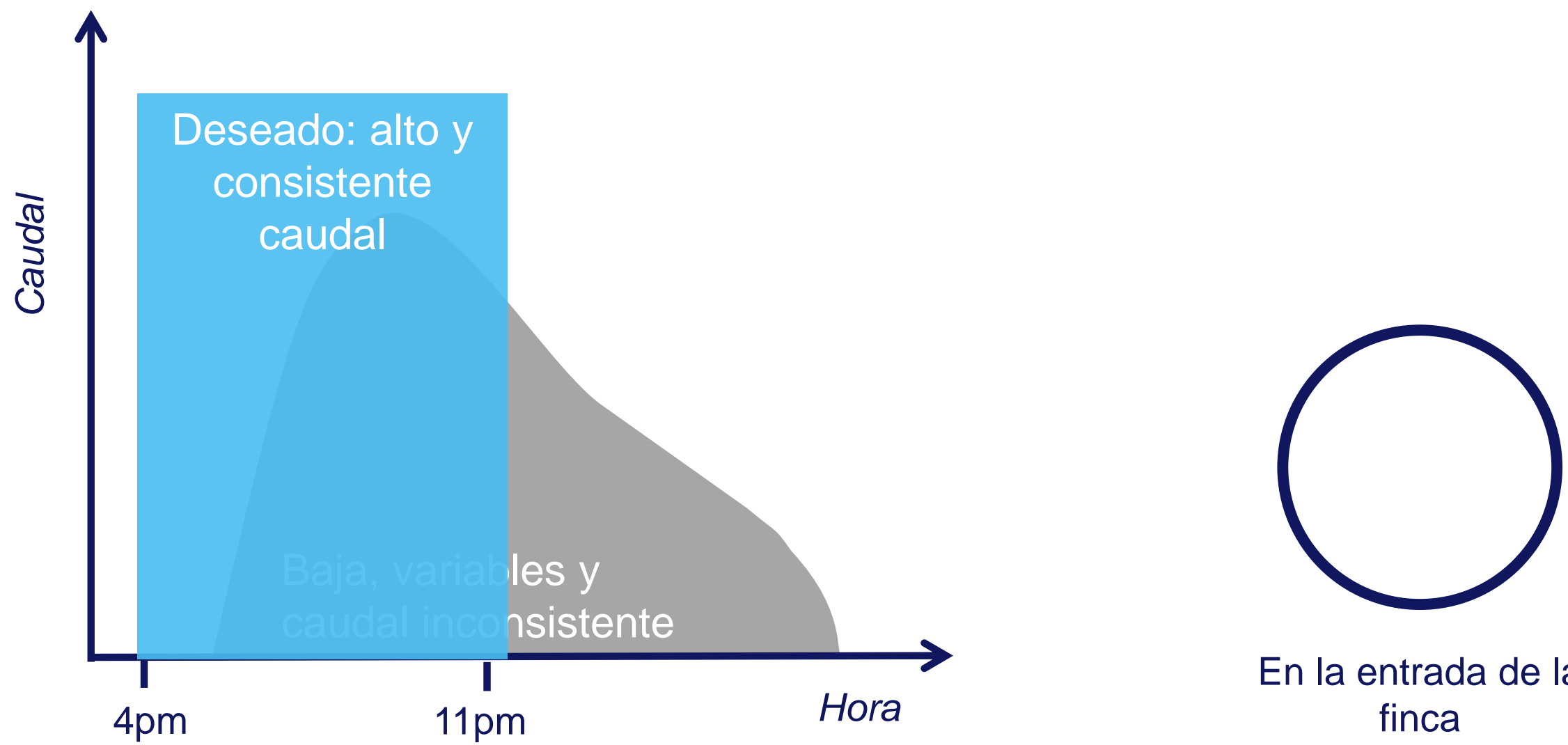

En la entrada de la finca 


\section{GMW - Australia}

$\checkmark$ Área de riego: $\mathbf{3 4 0 . 0 0 0}$ ha

$6.300 \mathrm{Km}$. de canales de riego abierto

$\checkmark$ Instalación de 12.000 Compuertas Rubicon

$\checkmark$ Todo el red gestionado por Rubicon TCC software

$\checkmark$ La eficiencia de transporte y distribución mejoró de un 70\% a un $85 \%$ y $90 \%=$ sistemas presurizados

$\checkmark$ No necesidad de balsas de regulación, ni bombeo, ni obra civil y entubado

$\checkmark$ Inversión MUCHO MENOR que en sistemas presurizados

$\checkmark$ SIN costes energéticos
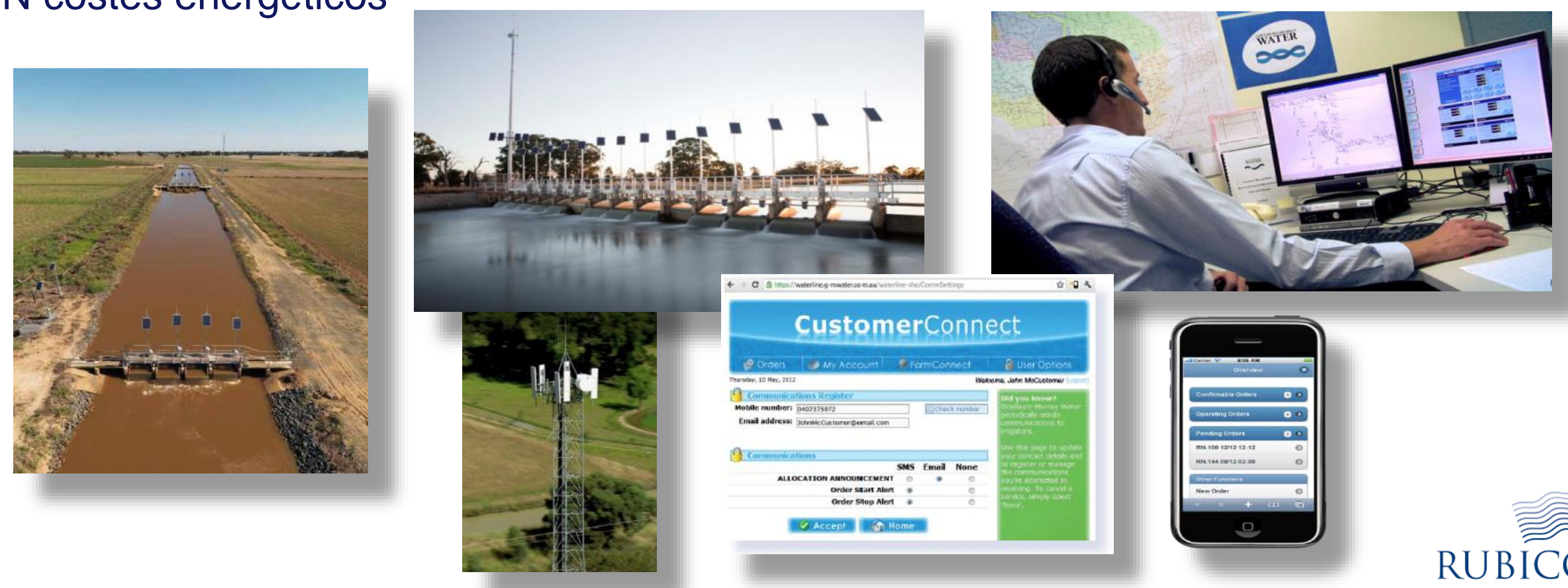


\section{Ejemplo: el poder de la automatización}

- Gran precipitación el 5 Febrero 2011

$\checkmark$ Más de 330 agricultores decidieron cancelar su uso por medio de teléfono e internet

$\checkmark$ Como consecuencia la demanda disminuyó 4.000 litros por segundo ( $4 \mathrm{~m}^{3} / \mathrm{seg}$ )

$\checkmark$ Con cada disminución de la demanda, todas las compuertas en el canal principal cerraron un poquito para guardar el agua en los canales

$\checkmark$ En lugar de verterse al final del canal 200.000 litros, se vertieron solo 7.000 litros, es decir se ahorró $96.5 \%$
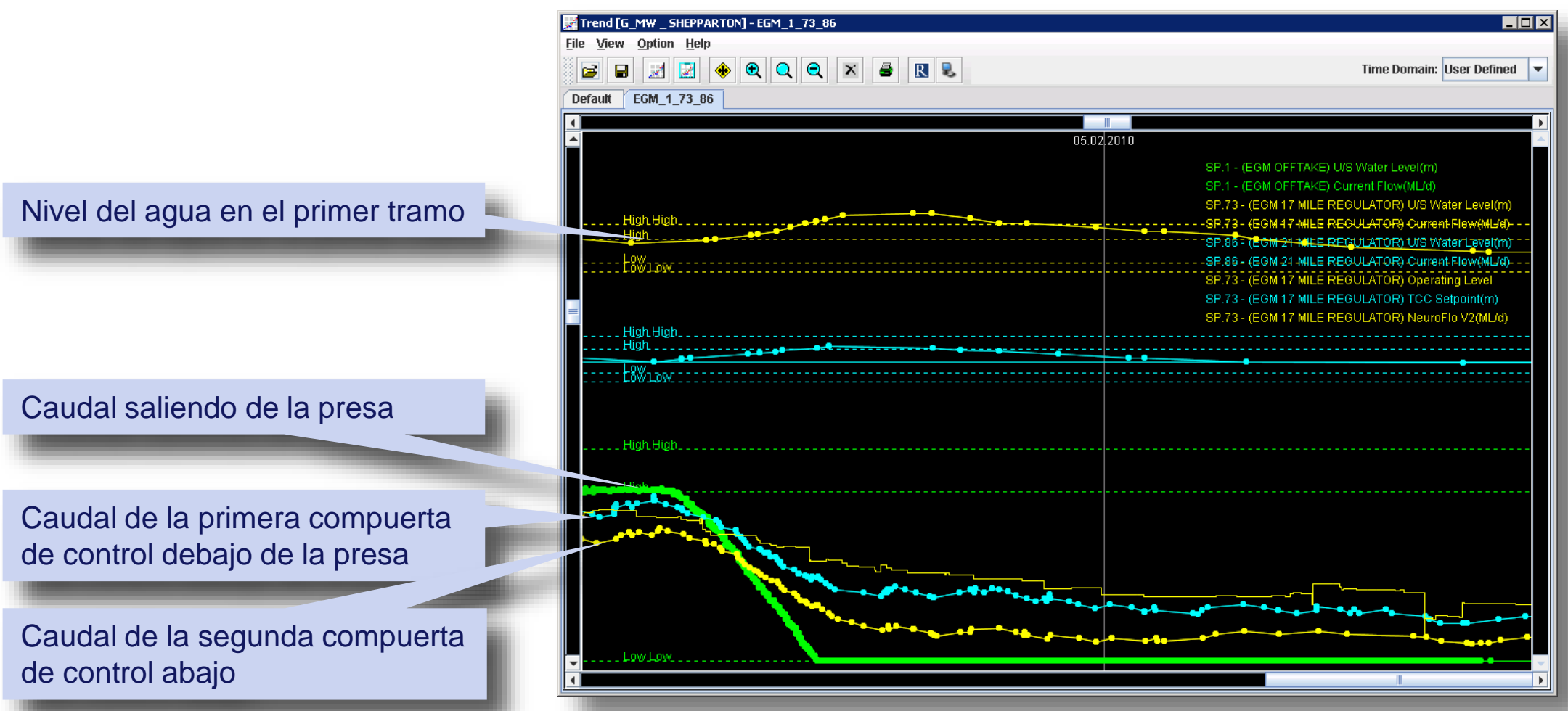


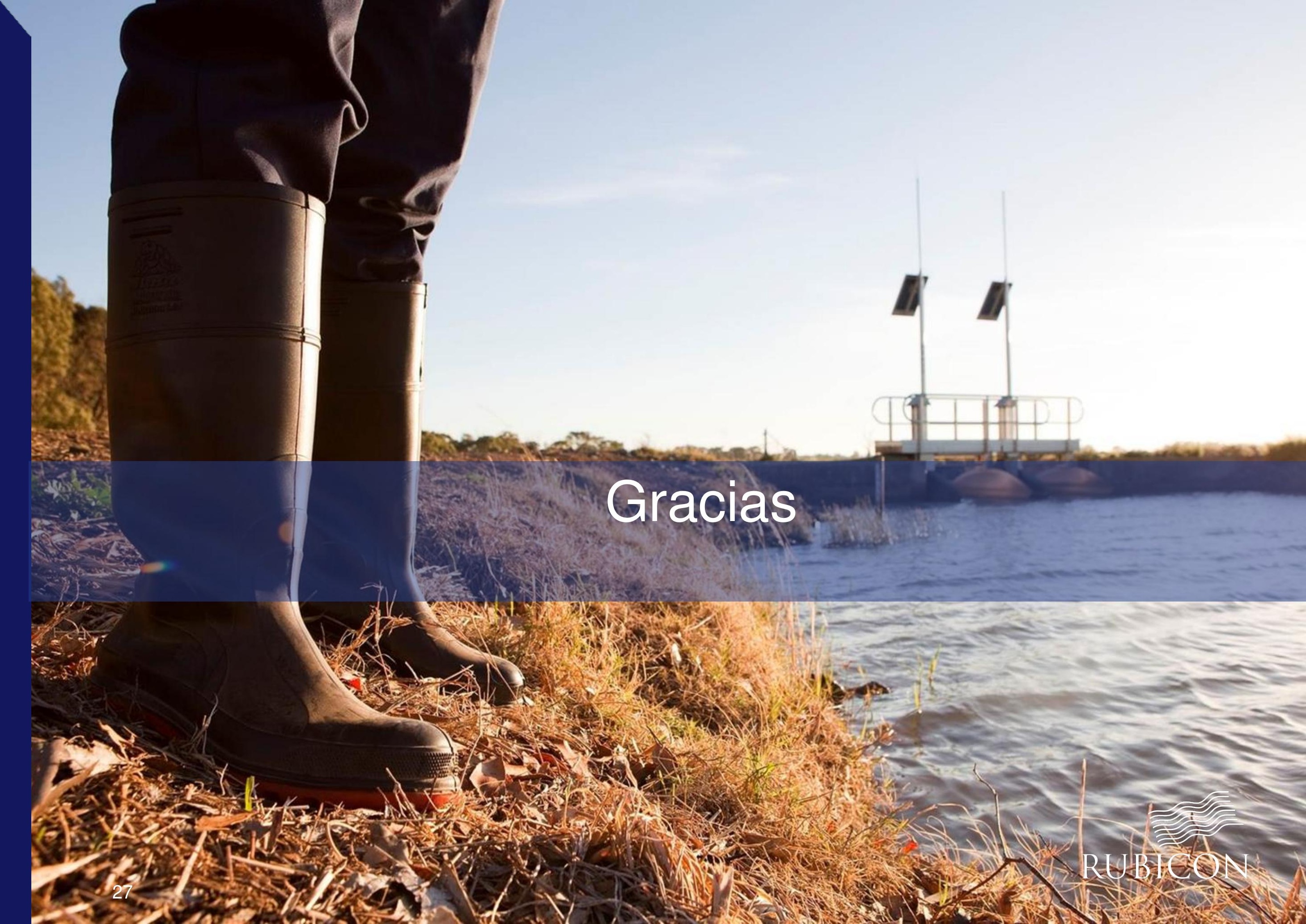

